\title{
Characteristics of "Chu Culture" Reflected in Folk Art of Gan Area
}

\author{
Li Feng ${ }^{1, a}$ and Nan Chen ${ }^{2, b}$ \\ ${ }^{1}$ School of Art, East China University of Technology, Nanchang, Jiangxi, \\ ${ }^{2}$ Library of East China University of Technology, Nanchang, Jiangxi, \\ a 875720874@qq.com, ${ }^{\mathrm{b}}$ 21854952@qq.com
}

Keywords: Chu culture characteristics; Folk art of Gan area; Jiangxi

\begin{abstract}
As a part of Chu territory in the history, Gan area in Jiangxi province has been influenced greatly by Chu culture. And some distinct characteristics of "Chu culture" are reflected in the folk art of Gan area nowadays. Just like Chu culture, Gan area's folk art emphasizes the thought of "harmony between man and nature", and folk "sorcery" has also been a common part in people's daily life. Moreover, the folk art advocates integrated open compatibility consciousness and patriotic and militarism. Besides, People adore red and love Dragon-Phoenix pattern. Finally, Lacquerware and bronze ware articles are often found in Gan area in Jiangxi province. Therefore, today's Gan folk art development is inseparable from the influence of Chu culture.
\end{abstract}

\section{Introduction}

In the Eastern Zhou Dynasty in China, there is a highly developed and unique regional culture in the South- Chu culture, and its brilliant cultural achievements attract worldwide attention. As an important part of Chu culture, the artistic form and style of Chu art fully embody Chu People's imagination and aesthetic consciousness. Chu culture and even the maturity of the whole Chu culture were produced in the unique historical environment at that time. Their origin is related to the historical civilization of the pre-Qin period. With the disappearance of $\mathrm{Chu}$, many cultural elements of Chu civilization were absorbed by Qin and transformed, and ultimately integrated into the unity of Han civilization. From the unearthed cultural relics, the earliest bronze, iron, gold and silver coins, silk fabrics, lacquerware, wood carving, bamboo weaving, Chinese writing brush, bamboo slip, silk manuscripts, painting on silk, bamboo chopsticks, wooden bed, bell and other material civilization are all created by Chu people; Strange thought of witch, ingenious words of Taoism (philosophy of Laozi, Zhuangzi), gorgeous thought of Li Sao (literature of Zhuangzi, Li Sao) and "Jing Chu eight tones instrument" are all originated in Chu. Chu people like to use the brush, which is initiated by Chu. Chu people like to wear clothes with baldric. They also like to eat taste of bitter, spicy, salty and sour food. They love chicken, birds, turtle and so on.

In the regional culture of each country in the Zhou Dynasty, Chu culture is an extremely important one. The main composition of Chu culture can be summarized as the six main parts: bronze casting, silk embroidery, wood bamboo lacquerware, art music, Laozi and Zhuangzi philosophy and Li Sao literature of Qu Yuan. From the current archaeological results, the most advanced bronze casting is from $\mathrm{Chu}$; the first iron is originated in the $\mathrm{Chu}$; for the lacquerware in pre-Qin period, Chu has the most lacquer with the best craft; the most creative silk embroidery is from Chu; Pre-Qin gold coins, silver coins are all from Chu. In philosophy, there are Laozi and Zhuangzi. In the literature, there is Li Sao of Qu Yuan. The originator of drama is Chu people You Meng. Yang Youji is a famous archer in Chu. The music, dance, painting, sculpture of Chu are extraordinary refined. "Eight music instruments" in Chu refers to gold, wood, earth, stone, silk, bamboo, leather and lagenaria. The chime and music and dance level is very high, which was accepted by all countries. In the political innovation, Chu people first set up the county system in current Hubei Jingmen, as an administrative division, which changed the aristocratic system, which led to military, land and tax reform. In the aspects of astronomy, calendar, mathematics, etc., Chu people have a unique contribution. In the mining, smelting, silk, lacquer, etc., Chu people have 
achieved unparalleled results, and Laozi and Zhuangzi philosophy, QuYuan Li Sao and Song Fu has become a notable doctrine.

Compared with the same period of other countries, Chu has a higher material civilization. For example, it has more developed agriculture; there are more advanced construction industry (it has Chu Cheng, Chu Shi, Chu Zhang Huatai and other buildings); it has more advanced metallurgical industry, silk industry, embroidery, and paint industry; advanced weapons manufacturing and so on. From the Chu culture that was taken as an ideology (spiritual wealth), it formed its own traditions and spirit, that is the tradition of Chu and the spirit of Chu. The Yangtze River Basin is one of the sources of Chinese civilization, Jiangxi region at that time in the history of changes, is always Chu territory. The life style of rice food and fish dish, plough with fire and irrigation with water had been very stable until the Han Dynasty. This geographical advantage and ease of access to the conditions have open features and are inclusive; so that local residents are easy to accept foreign cultural technology, while still adhere to the tradition of respect for nature.

\section{Emphasis on the Thought of "Harmony between Man and Nature", and Strong Effect of Folk "sorcery"}

"Harmony between man and nature" is one of the main features of Chinese traditional philosophy and an important feature of Confucianism. Confucian philosophy considers man and nature are "seamless". Life attitude key is "inside". It also considers the ultimate body of the universe and the moral principles of human unity. The people to achieve harmony between man and nature are the ideal personality. "The text of the text," said: "husband and adults who. Wenyan Qiangua records that for the great man, they can integrate the virtue of the world, the light of the Sun and Moon, the order of four seasons and the good or ill luck. Dong Zhongshu's Chun Qiu Fan Lu recorded that "integration of the same class is the harmony between man and nature". The ideal personality of Confucianism is the center of the relation between heaven and human. The integration of "nature law" and "human law" is essence of Confucianism. "Nature law" refers to the phenomenon of nature and its movement changes. "Human law" refers to the social norms that people should abide by. Confucian doctrine thinks that not only the coordination within the community should be achieved, but society should be in harmony with nature. "Harmony between man and nature", "Shangzhong", "rite" and so on, can be interpreted from the traditional Chinese art, thus we can see the Confucian culture has deep impact on traditional Chinese art.

Chu culture was created by the Chu people during the Warring States Period. It is the southern culture that has a tremendous impact when China has recorded history. In the south, Gan area had no need for intensive agriculture to strengthen grain production. Interpersonal contacts were not frequent as the north. So it's a regional culture around the middle and lower reaches of Changjiang River, forming the philosophy of revering Taoism. The grotesque in art creation is the presentation of disposition and the unity and relation of nature, which is the cultural and artistic root of Jiangxi.

Art style originates from the nature, which is embodied in the composition of the ideal and reality. "Learn widely from others' strong points outside, originate one's own style from inside", and illusion and reality, soul and material are never separated. They are all ascribed to "Tao", the perception of good fortune and are based on the heart, to achieve a kind of mingled harmony between the matter and me. They are the art image refined by the artist in the life, and the image shape with personality. This kind of "image modeling" is inseparable from the observation, refinement and transcendence of objective natural objects, but also requires natural fit, vivid artistic conception, complete charm and beautiful prospect. This kind of image performance has both a high degree of abstract generalization and subjective creativity, and is not the visual experience completely out of the pure experience. It has a better characteristic of aesthetic universality. The artist's performance no longer focused on the objective object but on the artist's personal inner feelings, conception, charm and interest, so that the art is embodied as a kind of philosophy, a spirit of self, emotional sublimation, making art become a realm, style, expression of tastes.

In terms of the custom of Chu culture, Chu area saved and developd the witch culture, that is, "beg the gods and ask of the diviner". "Chu people believe in the witch, and attach importance to 
the sacrifice against etiquette". Zhou enfeoffed the first Chu King Xiong Yi, and one of his duties is to offer peach and spiny arrows to the Zhou Dynasty to remove disaster. The first definition of witch is the words of a Chu people watching Shefu. He said: "people forms pure spirit, their wisdom can spread far away like light, their ability in dealing with matters can form a kind of realm and their function is to hear and perform, for man, called wizard and for woman, called witch". Mister Lv's Spring and Autumn Annals •Wugong Paper records "Wu Peng is great in medicine and $\mathrm{Wu}$ Xian is great in divination". Han Shu• Geography: "King Wu of Zhou conferred Chen to the posterity Gui of Shun, thus he was Hu Gong and married with Nvdaji. Honorable women sacrificed with witch, so the custom was keen on witch and ghost". Zheng Xuan Poetry Spectrum recorded "Daji had no child, keen on witch and wizard, praying with ghosts and gods song and dance, converted into folklore." Therefore, there is a saying "Witch and wizard are popular in Chu". Chu people used the "divination" approach to ask and decide things, choose the official, and even the throne of inheritance; of course, the witch respected by Chu people, "can be used for training, to be executed in the princes", can be proficient in Three Graves, Five Codes , Ba Suo, Jiu Qiu. When the Chu culture entered into the peak period, witch doctrine began to divert, its inheritors were still witch learning. The rationalization part turned to Taoism, and the sensibility part turned to Li Sao learning. Witch is a major feature of Chu culture. The occult Taoist thought and the romantic affection based on the "witch" style characterized by intuition and imagination. In the folk Gan area, the influence of "witchcraft" was strong, and the thought of unking-up of human and nature was popular. Witchcraft at the time had a serious social meaning. The divination made people believe the supernatural ability and effective way of contacting with ghost and god and their ancestors. The witchcraft activities are also the origin of Taoist philosophy and primitive science.

The Nuo opera in Jiangxi Pingxiang and other places still retains the tradition of Chu people, exorcism dance. From the text records, it first appeared in the Zhou Dynasty. The Rites of Zhou • Xia Gong • Fangxiangshi has detailed record: "Fangxiangshi covered bear's skin on hands, wore gold on eyes, black and red clothes, held dragger-axe and shield, leading hundreds of slaves for exorcism dance", which is a more complete exorcism dance record.

Nuo opera has a strong sense of worship, in a form of drama. The performers wear masks, playing wizards and spirits, in the form of dance, drama to invite God and entertain God, to get rid of the devil and disaster. It has some commonalities with the Chu songs and dances recorded in The Songs of Chu • The Nine Songs. The folk God Song and Funeral Song have simple tune, the rough original dance, which has close relations with Chu's witch dance.

Jiangxi Chu culture flourished later, and in the early Spring and Autumn Period, formed its own unique culture until the Western Han Dynasty. The custom of believing witch and ghost, mysterious strange art, fantastic and magnificent $\mathrm{Chu}$ literature and natural inaction Taoist spirit are the characteristics of Jiangxi and Chu culture. At the time of the scholar-bureaucrats and political level, Confucianism's morality, loyalty and ideals to regulate the family and rule the state dominated the country. But the Gan area was filled with witchcraft, adhered to the awe of spirits, and praying rites prevailed for thousands of years. These mysticisms were handed down to meet the people's psychological and religious needs, but also prepared conditions for the growth of a variety of ancient cultures and arts.

\section{Integrated Open Compatibility Consciousness and Patriotic and Militarism}

Shih Chi $\bullet$ Chu Family records that Chu people "opened up Jingshan wearing worn-out clothes, living in grass, trekking in the forest to serve the emperor". They have persistent pursuit, the spirit of seeking truth, and spirit of Bianhe offering jade; they have creative idea for chasing newness. They also have the spirit of forging ahead and self-motivation, not afraid of leap. King Cheng of Zhou conferred Xiong Yi "the land of viscount and baron", "area less than 100 li" and later the land was developed to "five thousand li, with a million soldiers wearing armour, thousands of chariot, the grains enough for 10 years", becoming one of the five overlords in Spring and Autumn. In the Warring States period, it has become one of the seven warring states. After being destroyed by Qin, there's also a saying "even Chu has three households, Qin must be destroyed by Chu." Later, only 
in 15 years, Xiang Yu, Liu Bang uprising exterminated the Qin Dynasty; theyhave the patriotism. Typical representative figures include Bianhe, Qu Yuan, Shen Baoxu, etc .; they have spirit being diligent in politics and loving the people, due diligence professionalism. The monarch and subjects in the period of King Zhuang of Chu is a typical example.

"Zuo Zhuan", "Han Feizi" records that a bird "three years without flying, but soars up into the sky with one start; three years without chirping, but blockbusting”, which is about the story of King Zhuang of Chu. The Lingyin (prime minister) Sun Shuao of King Zhuang of Chu was honest in performing one's official duties. When he went out, he only took literati level carriage. His meal had no meat, and his face appeared hungry color. They attached importance to agricultural production, leading the construction of China's first water conservancy project, that is, "Qisi" project; it has integrated open compatibility consciousness and patriotic and militarism. Chu people were open-minded, and they can integrate all ethnic science and technology of Central Plains and the South, making social and economic development of Chu develop fast. The bronze, weapons, bamboo carving, wood carvings of Chu came from behind. The wood from Chu was exported to the lower reaches of the Yangtze River and the Central Plains countries. The bark of Chu Qi Zi was even exported to Jin. The bows and arrows made by peach trees were exported to other countries. Feathers and bamboo arrow were sold to Qi, Lu. Gem, lacquerware, silk, and embroidery were sold to India, Southeast Asia. It's called "Southwest Silk Road". The productive King Zhuang of Chu can select and appoint talented, capable people and be good at accepting remonstrance. In the history of Chu, there were good officials such as Qu Yuan, Zi Wen, Sun Shuao and other good officials and great philosopher Laozi and Zhuangzi, as well as writers, such as Song Yu, Jing Cuo and Tang Le, Tang Le, and astronomers such as Zhu Rong, Gan Der and other outstanding figures. The important foundation of Chinese traditional philosophy Laozi and Zhuangzi are Chu people.

As the spiritual idea of Chu culture, Chu culture is mainly manifested as the spirit of self-esteem and martial spitrit. Huang Bosi in Song Dynasty said in his Edit Preface of The Song of Chu "the Sao poems of $\mathrm{Qu}$ Yuan and Song Yu all came from Chu, described $\mathrm{Chu}$, commemorated Chu and naming Chu products, so they were called The Song of Chu." Many idioms stories, such as "Bi Lu Lan Lv", "Yi Ming Jing Ren", "Zhe Ge Wei wu", "Bai Bu Chuan Yang”, "Bian Chang Mo Ji”, "Hu Jia Hu Wei", "Hua She Tian Zu", "Jing Gong Zhi Niao" all from Chu, and had deep roots with Chu. After being destroyed by Qin, Chu people Nan Gong said "even Chu has three families, Qin must be destroyed by Chu." This is not only a prophecy, but also the vow. Sure enough, in sixteen years, Qin was destroyed by the peasant uprising with the descendants of Chu as the main force. This patriotic spirit of Chu people surpassed the time and space and integrated into the blood of the Chinese nation, from generation to generation.

\section{Advocate of Red and Dragon-Phoenix Pattern}

Chu people advocated red. Among many colors, red (chemical stability is good, but also a symbol of blood and life) attracted more, they wore red clothes. Mo-tse - Gongmeng records "at one time, King Zhuang of Chu wore red hat and silk ribbon, as well as deep red clothes to rule the country well." Deep red clothes refer to the red wide-sleeved gowns. Chu people like to paint red on the building. Gио Yи $\bullet$ Сhиуи Volume One records that Ling King built Zhanghutai that had the beauty of "Tong Lou", which refers to the red color painted on Chu King Palace. Chu people like to apply red tones on daily necessities. The unearthed plate, spoon, cup, pot wall from Chu tomb was painted to exquisite pattern with red. Chu people like to make minium embroidery on the silk fabrics.

Chu people "advocating red" custom originated from Chu ancestors' basic beliefs of "worship of the sun, fire and phoenix". This belief is based on the worship of nature and their ancestors. Chu ancestor Zhu Rong was the God of fire "can commend the light of heaven and earth, have surrendered to Yan Emperor." "Yan Emperor is the sun". Sun is the embodiment of Yan Emperor. Worship of sun and fire is also the embodiment of religious ancestral worship.

Dragon, Zuozhuan •Zhaogong Seventeen Year records that "Tai Hao used dragon to record events, taking dragon as the teacher". A large number of documents and archaeological data have proved that $\mathrm{Fu} \mathrm{Xi}$ "human head with snake body". Snake is the totem of Fuxi tribe. The total totem of 
Chinese dragon is based on the snake, and it's the convergence of multi-ethnic totems. Wen Yiduo in the Fuxi Research pointed out the dragon was a complex made by a number of different totems, because the tribe merger mixed totems." The main part and tone is snake. "The so-called dragon was just a big snake probably before totem merger. The snake is called "dragon", and later the snake totem tribe absorbed many other totem groups. The snake accepted the four feet of mammals, the head of horse, the tail of mane, the horns of deer, the claws of dog and the scales and beard of fish, so the dragon formed what we now know. The formation of dragon totem is a symbol of Chinese main blood convergence and the foundation of culture. Since then, Chinese people have a common name - "the descendants of dragon", with the same ancestors - Fu Xi. Under the banner of $\mathrm{Fu} \mathrm{Xi}$, more nations united to one China. Fuxi thus became the wide range representative of Chinese nation's blood and culture. Chu people advocated phoenix, which is the identity of Chu culture. Chu people took "God Bird" phoenix as their own totem. White Tiger Tongyi - Five Elements records the god of the South Zhu Rong, "his spirit is bird, and Yan Emperor is Luan", Luan is phoenix. Phenix is the embodiment of the God of fire. Phoenix worship is to respect their own nation, respect themselves and ancestors.

Dragon and phoenix pattern is the typical decoration of Chu, and now is still evolving, loved by Jiangxi people. Gan area folk art decoration advocates overelaborated and fine, rich and magnificent color. The artifacts are often known for color fantasy, and irregular lines with a strong sense of movement. The pattern often deforms, resolves and combines. The abstract techniques are widely used. Or the pure line is used to perform a phenomenon. The pattern includes geometric pattern, animal and plants and characters story. For the plant pattern, it strictly forms square and rhombus according to latitude and longitude and diagonal, playing both decorative role and skeleton role. The animal pattern head realism, body exaggerated deformation and animal combination phenomenon is more common. It is significant as a cultural symbol, which is the result of ancient original thinking and primitive worship.

\section{Lacquerware and Bronze Ware Article}

In the world, the 300 years from the 6th century BC to the 3rd century BC, the East and West culture were competing. We can put the Chu culture as a representative of world civilization with ancient Greek culture in the same period. The bronze smelting, cast iron, silk, lacquerware were earlier than ancient Greece. Lacquerware not only had a wide variety, but also were widely used in all aspects of social life. They mainly include life appliances, furniture, musical instruments, writ instruments, weapons, carriages and horses tools, handicrafts and funeral appliances. At that time, the lacquerware was thick wood-based, and thin wood was less. There were very few dry lacquer and bamboo embryo. Production methods vary due to material and shape, such as wood is mainly made with 3 methods, including hacking with an axe, digging and carving, bamboo chop system and saw the main method. The shape is different, and the theme is rich, including the birds and animals in the real world, real and realistic, and resembled. There were legendary "God bird", "God animal" combining dragon and phoenix with the animals in real life. Some are grand and peculiar, and some are small and exquisite, very delicate and beautiful. Painting technology is very developed, not only rich and colorful, and the pattern content and form are very complicated. The main pattern includes dragon, phoenix, beast, birds, triangular moire, dance pattern s, and so on. The lines were outlined staggered, with beautiful patterns, and full of change. The color matching is harmony and sightly. In addition, the Chu lacquerware also widely used gold, silver drawing method, and decorative foil decoration techniques were also found.

Jiangxi in Chu is rich in lacquer tree and raw materials, with humid environment, the implements are perishable, so far unearthed lacquerware in the Warring States Period was seldom found. Lacquerware became the cultural characteristics of Chu. During the Warring States period, the lacquer craft was the top in the world. From the lacquer tonic and the lacquered technology, it can be described that the modern folk lacquerware has many kinds of materials for carving, spin-vibrating, rolling and sculpture, for example, in the process of clamping and twisting production: painted gray on the mould, applying the fabric and then scraping, and then stripping, 
polishing and paintin. The process is basically similar.

There are a number of bronze wares with complicated varieties. In addition to the sole utensils of $\mathrm{Chu}$, even in the Central Plains region for the same utensils, the shape also has its own characteristics. The entire utensils group reflected delicate Chu style most vividly. In terms of decoration, the unique decoration of Chu is not much, but even with the same pattern of the Central Plains, Chu people also modified to make it show a different structure and style. For the most rituals, whether they are burial objects or not, the motifs are from complex to simple, and become plain, and at the same time there are some exquisite single-piece daily bronzes, especially the artifacts and artful patterns are very rare. In addition to mastering the skilled smelting technology, casting technology has become increasingly mature. Chu people at this time learned from the others, combining the smelting technology of Yangyue and the Central Plains of casting technology together to produce a large number of high-quality bronze. In the casting process, sub-casting welding technology was fully grasped and promoted. The loss of wax and leakage lead casting process was the original creation of them, so that their casting process is the first-class. At this time the type of bronze greatly increased, but almost were the aristocratic daily life tools, often with the traces of usage. In the artifacts and decoration there's no longer imitation but following their own tradition. According to their own aesthetic taste, their own style and changes were performed. Compared with the Central Plains' similar artifacts, they have changed a lot, and began to appear unique artifacts. The decorative patterns were mostly the common patterns in the Central Plains, but as for the form of expression, combination of relations and decorative techniques, etc. there are many rare features with the Central Plains. The reliefs, round carving, openwork carving and so on were used widely and skilled, while the mounted technology of copper sacrificial has begun to be used. These features make the Central Plains rituals leave behind.

Chinese civilization is originated from the Yellow River and the Yangtze River. With the anthropology, archaeological progress in the 20th century, the statement that Yangtze River is one of the sources of Chinese civilization has been confirmed. The strong power of Chu has arisen in the middle and lower reaches of the Yangtze River since Zhou Dynasty by integrating Bapu, Nan Man, Dongyi and Wu Yue culture, and has become the mainstream culture of southern China. It became the token of South and North China culture together with the Central Plains rites advocating political authority. Until today, due to the geographical environment and historical tradition of legacy, keeping the natural way of life can also be seen in the Gan folk art. The influence of Chu culture is visible, but also on many other aspects like the folk customs. With the deep excavation work of Jiangxi Xingan Dayanghzou, and experts' and scholars' deep work of folk art research on the Nuo opera in Pingxiang, Nanfeng and other places, the outline of Jiangxi Chu culture gradually emerged. The rediscovery and understanding for the civilization of the Yangtze River in the south, and the re-definition of the status of Gan area Chu culture in Chinese civilization leads to the study of local folk culture research. After hundreds of years of development, Jiangxi and Chu culture does not disappear because of regime change. With the passage of time, the essence of Chu culture has become the core of Chinese culture. Chu style is still retained in the descendants of Chu ethnic. Until today, it is still reflected in the spiritual beliefs, customs and daily life details, and filled with infinite vitality. Today's Gan folk art development is inseparable from it!

\section{References}

[1] Shengzhong Lv. Modeling Original [M]. Life Reading New Book Sanlian Bookstore. 2002, 12 (In Chinese)

[2] Daoyi Zhang. Daoyi Zhang anthology Volume Two [M]. Anhui Education Press. 2001,10 (In Chinese)

[3] (USA) Elam, Leshan Li. Design Geometry: Study on the Proportion and Composition [M]. China Water Resources and Hydropower Press, 2003 (China)

[4] Tiemu Li. Mathematics and Philosophy [M]. Earthquake Press, 1999 (In Chinese)

[5] Huilong Tian, Hongmin Wu, Lan Wu. The Art Design Characteristics of Chinese Folk Patterns [J]. Packaging Engineering, 2006,27 (6); 353. (In Chinese) 
[6] Jiahu Bao. Paper-cut Art [M]. Jinan Shandong Education Press. 2000 (In Chinese)

[7] Daoyi Zhang. Chinese Folk Art Dictionary [M]. Jiangsu Fine Arts Publishing House. 2001 (In Chinese) 